\title{
PERAPEN SIMBOL PENGUATAN IDENTITAS WARGA PANDE DI BALI
}

\author{
Oleh: \\ A.A. Kade Sri Yudari \\ Pascasarjana Universitas Hindu Indonesia \\ Denpasar \\ sriyudari15@gmail.com
}

\begin{abstract}
God Almighty in his manifestations as Lord Brahma, Vishnu and Shiva (Tri Murti) is an object of substance that can be reached by Hindu society to be revered. Of the three manifestations of God, Pande's ancestors were worshipers of God Brahma as the main deity. This is related to the profession that put into operation is 'memande' at perapen (per-api-an) to make household appliance and various weapons. Brahma god symbolized as fire (agni) is of course considered the closest in providing holy rays, protection, rezeki abundant and prosperity for the class of Pande in carrying out his profession. The worship of the God Brahma is evident during the celebration of the Tumpek Landep holy day which falls every 210 days. Tumpek Landep used as a medium of respect for God in the form of Brahma as the whole nature creator included of earth elements made from metal, such as iron, steel, gold, silver, and copper. Therefore, between Tumpek Landep and Perapen are closely related and even become a symbol of identity booster for the existence class of Pande in Bali.
\end{abstract}

Keywords: Perapen, Identity of strong, Class of Pande.

\begin{abstract}
Abstrak
Tuhan Yang Maha Esa dalam manifestasinya sebagai Dewa Brahma, Wisnu dan Siwa (Tri Murti) merupakan objek substansi yang dapat dijangkau oleh masyarakat Hindu untuk dipuja. Dari ketiga manifestasi Tuhan itu, leluhur warga Pande merupakan pemuja Dewa Brahma sebagai dewa utama. Hal ini terkait profesi yang dilakoninya yaitu 'memande'di perapen (perapi-an) membuat alat rumah tangga dan berbagai senjata. Dewa Brahma yang disimbolkan sebagai api (agni) tentu saja dipandang paling dekat dalam memberikan sinar suci, perlindungan, limpahan rejeki dan kesejahteraan bagi Warga Pande dalam menjalankan profesinya. Pemujaan terhadap Dewa Brahma terlihat jelas pada saat perayaan hari suci Tumpek Landep yang jatuhnya setiap 210 hari. Tumpek Landep dijadikan media penghormatan terhadap Tuhan dalam wujud Brahma sebagai pencipta alam semesta termasuk unsur bumi yang berbahan baku logam, seperti besi, baja, emas, perak, dan tembaga. Oleh karena itu antara Tumpek Landep, dan Perapen sangat berkaitan bahkan menjadi simbol penguat identitas bagi eksistensi warga Pande di Bali.
\end{abstract}

Kata kunci: Perapen, Penguatan Identitas, Warga Pande. 


\section{PENDAHULUAN}

Sejarah menyebutkan bahwa pada abad VIIVIII M di Bali berkuasa para raja dari dinasti Sanjaya (kerajaan Mataram Hindu) yang berpusat di Jawa Tengah. Namun jauh sebelumnya berdasarkan peninggalan arkeologi yakni pada zaman Bali Mula, pulau Bali telah dihuni oleh penduduk yang sudah mahir membuat peralatan terutama dari batu salah satunya disebut sarkopagus (peti batu). Hal ini menjadi salah satu bukti bahwa sarkopagus buatan manusia yang memiliki profesi 'memande' yang hidup menghuni pulau Bali zaman pra Hindu.

Keberadaan desa Trunyan di Kintamani diyakini sebagai desa tua dengan peradaban megalitik sebelum kedatangan orang Hindu di Bali. Mereka memiliki kepercayaan bahwa dewa tertinggi bernama Ratu Sakti Pancering Jagat yang dikenal dengan nama lain Da Tonta. Dalam agama Hindu tidak ada Dewa yang bernama Da Tonta, bagi orang Trunyan beliau adalah leluhur/ kawitan yang paling dimuliakan. Da Tonta disemayamkan pada sebuah palinggih yang disebut Pura Dewa Pande. Dengan melihat istilah 'pande'diperkirakan pada saat itu warga pande telah menempati desa Trunyan walaupun saat ini sudah tidak ada lagi yang 'memande' di sana.

Upaya pewarisan kearifan local dari generasi ke generasi tidak ada jaminan bahwa kearifan local tersebut tetap kokoh menghadapi globalisasi yang menawarkan gaya hidup semakin pragmatis dan konsumtif. Secara factual dapat kita contohkan bagaimana kearifan yang sarat nilai skill dan estetika nyaris tidak terimplementasikan dalam praktek kehidupan sehari-hari di Trunyan. Hal ini ditujukan pada etnis tertentu seperti warga Pande di Trunyan dengan kearifan lokalnya 'memande' yang bersifat semata-mata menjaga dan melestarikan tradisi nenek moyang/leluhurnya. Kondisi seperti itu bisa disebabkan oleh factor intern seperti adanya bencana alam dan factor ekstern yakni pengaruh globalisasi yang membuat mereka hijrah ke lokasi yang baru dan lebih aman dan menguntungkan bagi masa depan generasinya. Sehingga mereka harus meninggalkan tempat semula mencari perlindungan dan menjalani kehidupan bersama generasi penerusnya.

Identitas seorang pande ada dua ciri khas, yakni identitas fisik dan identitas simbolik yang masih tetap dipertahankan oleh warga pande. Identitas fisik yakni berupa pekerjaan, tempat bekerja, dan benda yang dihasilkan. Sedangkan identitas simbolik berupa nama, warna dan tradisi. Bagi warga pande yang tidak 'memande' mereka tetap membuat 'Perapen' untuk mengenang dan sebagai wujud rasa bakti terhadap leluhur. Tentang identitas nama, warga pande memiliki nama depan 'Pande' yang membedakan dengan warga/soroh lainnya.

Pada hari Tumpek Landep warga pande melaksanakan persembahyangan membersihkan dan menyucikan benda-benda pusaka leluhur seperti; keris, tombak, pisau, dan alat-alat yang digunakan untuk 'memande'. Pada hari itu juga mereka menghias 'Perapen' (perapi-an) dengan kain warna merah dan sesaji yang lebih dominan bahan-bahannya berwarna merah. Keyakinan terhadap warna merah dimaknai sebagai pemuja dewa Brahma (salah satu Dewa dalam Tri Murti) yang menciptakan alam semesta serta isinya. Dalam kaitan dengan dewa Brahma sebagai dewa pencipta pada hari Tumpek Landep dipahami merupakan hari kelahiran segala sesuatu yang ada, diciptakan, bertumbuh dan berkembang di alam semesta ini. Oleh karena itu, inti dari peringatan hari Tumpek Landep adalah penghormatan terhadap dewa Brahma, melalui ciptaannya yakni; segala unsur bumi, manusia, teknologi dan hasil karyanya.

Di satu sisi bagi warga Pande peringatan hari tumpek landep dimaknai sebagai pemujaan terhadap dewa Brahma. Brahma adalah manifestasi Tuhan Yang Maha Esa pada saat mencipta dengan wujud bermuka empat menghadap ke empat penjuru mata angin. Brahma berasal dari suku kata 'brh' yang artinya tumbuh, berkembang, berevolusi, bertambah besar, yang meluap dalam diri. Dewa Brahma dengan nama lain dewa Agni yakni manifestasi Tuhan yang memberikan energi dan menguasai api. Api adalah bentuk kekuatan yang mengisyaratkan bahwa untuk menciptakan sesuatu harus memiliki energi. Tanpa energi tidak ada ciptaan apapun di dunia ini. Dalam ajaran Hindu, ada kepercayaan energi alam semesta (buwana agung) dengan energi dalam diri manusia (buwana alit) harus selaras dan seimbang.

Di sisi lain beberapa kalangan masyarakat 
secara umum selain warga Pande memaknai hari Tumpek Landep merupakan media pemujaan terhadap dewa Siwa dalam manifestasinya sebagai Sang Hyang Pasupati yang memberi jiwa segala ciptaan di dunia termuat dalam lontar Sundarigama. Kata 'tumpek' berasal dari 'tu'(metu) diartikan bertemu, dan 'mpek' diartikan akhir. Sehingga kata'tumpek' dipahami sebagai hari pertemuan Panca Wara terakhir (keliwon) dan Sapta Wara terakhir (saniscara). Sedangkan kata 'landep' diartikan tajam, lancip, runcing karena itu diadakan upacara terhadap pusaka yang memiliki sifat tajam dan lancip.

Landep dari kata Tumpek Landep memiliki filosofi tonggak penajaman citta, budhi, dan manah (pikiran). Dengan demikian tumpek landep merupakan tonggak untuk mulat sarira/ introspeksi diri memperbaiki karakter agar selalu berpikir jernih dan berperilaku sesuai dengan nilai dan ajaran agama. Dengan pikiran, budhi, dan citta yang tajam diharapkan dapat memerangi kebodohan, kegelapan, dan kesengsaraan serta mampu menekan perilaku buthakala yang ada dalam diri. Umat Hindu bukanlah menyembah benda-benda teknologi, tetapi umat memohon kepada Ida Sang Hyang Widhi Wasa dalam manifestasinya sebagai Ida Bhatara Sang Hyang Pasupati yang telah menganugerahkan kekuatan dan kesejahteraan pada benda tersebut sehingga mempermudah dalam menjalani kehidupan (dharma wacana Ida Pedanda Gede Made Gunung).

Sang Hyang Widhi dalam manifestasinya sebagai dewa Brahma, Wisnu dan Siwa (Tri Murti) merupakan tiga objek substansi yang dapat dijangkau oleh umat Hindu untuk dipuja. Sudut pandang dan keyakinan yang berbeda dalam kaitan pemujaan salah satu dewa pada saat hari tumpek landep oleh umat Hindu di Bali tidak dapat dipersalahkan sepanjang logikanya masuk akal dan argumennya bisa dipertanggung jawabkan. Yang menjadi point persoalan pada tulisan ini mengapa 'perapen' selalu dikaitkan dengan warga pande dan bagaimana sejarah dan eksistensi warga pande yang ada di Bali.

\section{PEMBAHASAN}

\subsection{Eksistensi Perapen dan Warga Pande di Bali}

Perapen adalah bangunan yang dipergunakan sebagai tempat melakukan aktivitas khususnya melakukan pekerjaan mengolah bahan logam yang menghasilkan barang bernilai seni seperti keris dan gamelan. Perapen juga dipandang sebagai tempat suci karena di dalamnya terdapat sebuah palinggih yang diyakini sebagai tempat memuja Dewa Brahma. Karena itu wanita yang sedang mengalami menstruasi tidak diperbolehkan masuk ke areal perapen, demikian juga alat-alat yang terdapat di dalam perapen jika dipakai dan dibawa ke luar areal perapen harus disucikan kembali dengan sesajen prayascita. Secara etimologis perapen berakar kata 'api' dengan imbuhan per-an, a+i=e disandi suarakan menjadi perapen (Jawa Kuno), namun di Bali sering diucapkan dengan cepat menjadi prapen

Perapen pada zaman dahulu hanya boleh dibangun di bagian selatan pekarangan rumah seorang pande berdasarkan arsitektur tradisonal. Seiring dengan perkembangan zaman perapen tidak lagi dibuat berpatokan pada arah selatan melainkan mengikuti kondisi tempat pekarangan seorang pande. Perapen adalah sebutan untuk tempat per-api-an dalam industri pande besi. Perapen ini berupa lubangan kecil dengan batu di bagian kiri dan kanannya. Perapen inilah yang menjadi wadah api untuk membakar logam, besi-besi yang akan dibuat alat-alat pertanian, gamelan, termasuk

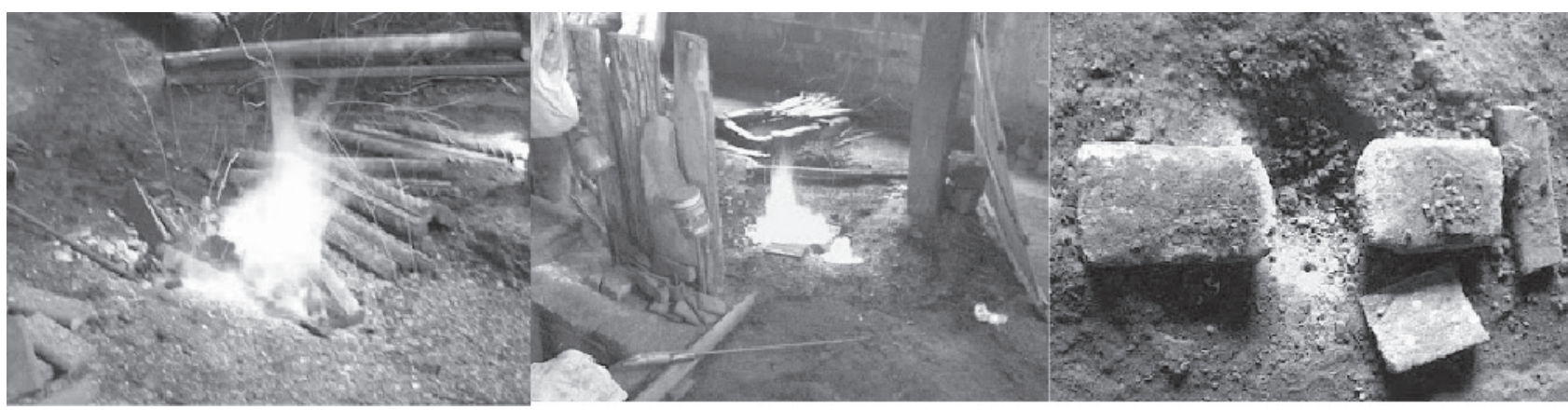

Gambar 01, 02 , 03. Perapen Tradisional 
senjata seperti keris dan lain-lain.

Perapen terhubung dengan blower menggunakan pipa paralon dari besi. Perapen harus dijaga dan dirawat agar kondisi api yang dihasilkan dapat maksimal. Hal ini sangat berpengaruh terhadap produktivitas industry sehingga setiap hari harus dibersihkan untuk menghilangkan sisa-sisa pembakaran besi yang disebut dengan istilah 'tai besi'. Setidaknya sebulan sekali perapen dirombak dengan mengganti batu-batu disampingnya dan mengatur kembali lubang di dalamnya. Batubatu di samping kanan-kiri semakin lama pasti terkikis. Jika tidak dilakukan perombakan, api yang dihasilkan di perapen tidak maksimal.

Di zaman modern 'perapen' disebut juga pendiangan atau fireplace (Ing) adalah sebuah struktur arsitektur yang terbuat dari batu, logam dan batu bata yang didesain bisa mengandung api. Perapen adalah sebuah tempat api yang digarisi batu atau bata tanpa sebuah oven digunakan untuk memanaskan seperti tujuan awalnya dibuat untuk memasak makanan. Pada abad pertengahan perapen diletakkan di tengah balai pada sebuah rumah. Selanjutnya tahun 2010-an, perapen digunakan untuk menciptakan suasana santai sekaligus menghangatkan ruangan. Perapen modern memiliki efisiensi panas yang bervariasi, tergantung pada kecanggihan desainnya. Secara historis perapen digunakan untuk menghangatkan sebuah hunian, untuk memasak, memanaskan air, mencuci pakaian dan berbagai penggunaan dalam rumah tangga.

Perapen yang semula berfungsi untuk mengolah besi menjadi peralatan sehari-hari, kini bertambah menjadi asesoris kebutuhan rumah tangga agar Nampak lebih bergaya. Perapen yang biasanya diadopsi oleh rumahrumah klasik-kontemporer, kini dengan konsep yang modern pun bisa menambahkannya dalam listing asesoris bangunan rumah yang bisa diaplikasikan ke dalam bentuk konsep apa pun. Tungku perapen modern memang tidak selalu digunakan, hanya pada musim dingin, hujan dan salju atau cocok untuk rumah yang berada di pegunungan. Hal ini sangat penting sebagai alternative pemanas, yang lebih natural dan tidak membutuhkan atau menghemat listrik

Api berada pada sejenis rongga seperti tungku, berisi cerobong asap atau saluran lainnya yang berfungsi untuk mengeluarkan asap atau gas buang. Sebuah perapen modern memiliki ciri; berisi pondasi, tungku api, rongga tempat pembakaran, tudung, saluran cerobong asap apabila berfungsi untuk memasak dan tempat mencuci pakaian, ada jeruji, ambang, balok ambang, panel dekoratif, pengatur aliran udara, ruang asap, leher dan pipa pembuangan. Memperhatikan ciri perapen modern sudah pasti perapen yang dimaksud dalam tulisan ini adalah perapen tradisional yang disakralkan oleh warga pande dan selalu terdapat sebuah palinggih di dekatnya sebagai pemujaan Dewa Brahma.

Ajaran agama Hindu India, mempercayai Dewa Brahma sebagai pencipta alam semesta dengan sebutan Hiranyagarbha atau Prajapati. Dalam filsafat Adwaita, Upanishad dan Bhagawadgita, Brahma dipandang sebagai salah satu manifestasi dari Brahman (konsep Tuhan dalam Hinduisme). Sedangkan dalam Purana dan kitab Mahabharata Dewa Brahma merupakan leluhur dunia yang muncul dari pusar Dewa Wisnu. Penggambaran Dewa Brahma sebagai sosok Dewa dengan empat muka menghadap keempat penjuru mata angin (Caturmukha Brahma) melambangkan catur Weda dan catur Yuga (siklus waktu). Sedangkan dilukiskan sebagai pria tua yang berjanggut putih dimaknai sebagai leluhur dari alam semesta (jagat raya).

Demikian juga symbol alat-alat yang dipegang keempat tangan seperti; aksamala/tasbih sebagai symbol tiada awal dan tiada akhir; Sruk (sendok besar) dan surpa (sendok bisaa) symbol dari upacara yadnya; kamandalu/kendi symbol dari keabadian; pustaka symbol dari ilmu pengetahuan. Wahana angsa putih symbol kebijaksanaan dan kemampuan memilah baik dan buruk; bunga Padma merah symbol kesucian lahir bathin. Dewi Saraswati adalah sakti Dewa Brahma sebagai dewi ilmu pengetahuan. Makna yang tersirat bahwa suatu penciptaan atau suatu karya tanpa landasan ilmu pengetahuan menjadi sia-sia. Itulah sebabnya warga pande senantiasa memuja Dewa Brahma sebagai dewa utama pada palinggih yang ada di perapennya.

Dalam kehidupan sehari-hari masyarakat di Bali, Dewa Brahma penggambarannya tidak jauh berbeda dari India. Brahma diyakini sebagai dewa yang bersthana di dapur, pelindung arah selatan, bersenjata gada, wahana angsa, 


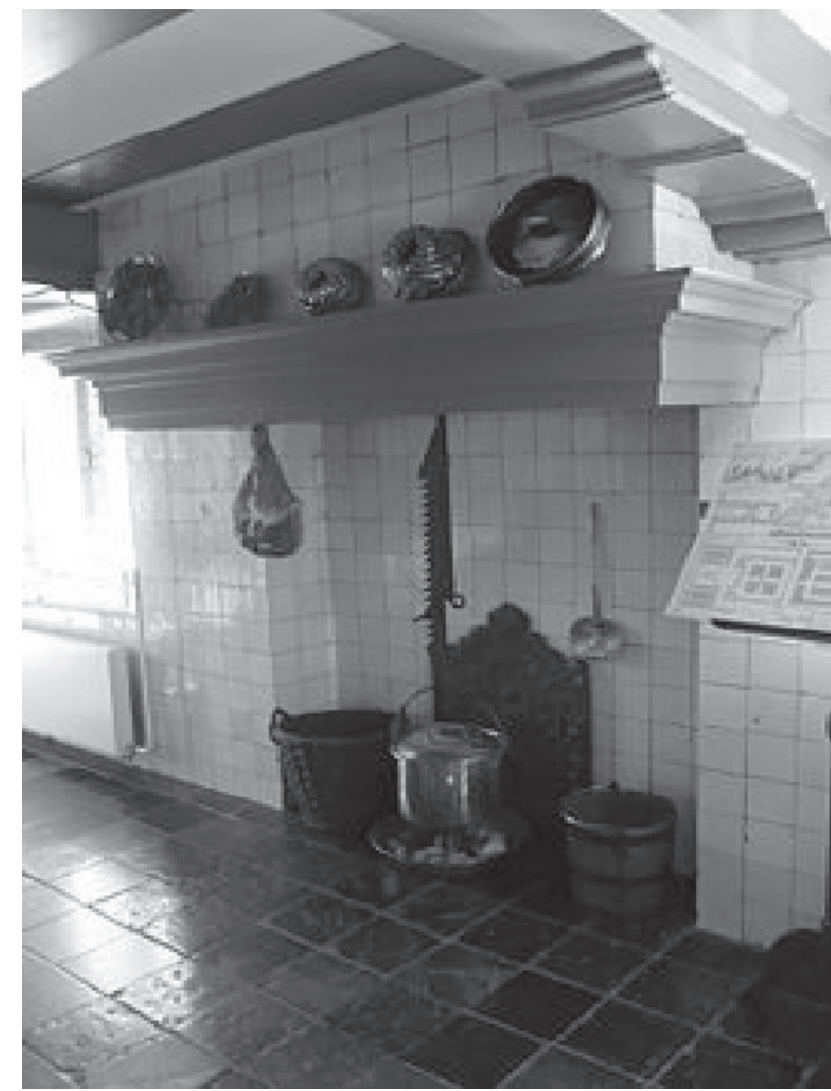

Gambar 04. Prapen Kontemporer

saktinya Dewi Saraswati, dan atribut serba merah. Brahma Stawa dewa Brahma yang dilafalkan pada saat pemujaan di perapen oleh Jro Mangku Pande sebagai berikut;

Om, brahma prajapatih sresthah, svayambhur varado guru, padmayonis catur vaktro, brahma sakalam ucyate. Om, namostu bhagawan agni,sarvoktema hutasana, vajra sara maha sara, dipto gnih jvalanas tatha.

\section{Artinya:}

Dewa brahma dewa segala makhluk, dia yang paling mulia, dia yang memberikan anugerah pada guru, dia yang dilahirkan dari bunga teratai, yang berwajah empat, demikianlah brahman yang sempurna. Dewa agni peredam segala kejahatan, yang lahir dari benih keemasan, badan dari alam semesta, dan merupakan kebahagiaan yang tertinggi

Sampai saat ini perapen di Bali masih tetap dipertahankan, dan dilestarikan keberadaannya sebagai simbol penguatan identitas warga pande, walaupun mereka tidak melakukan aktivitas 'memande'. Eksistensi perapen di Bali

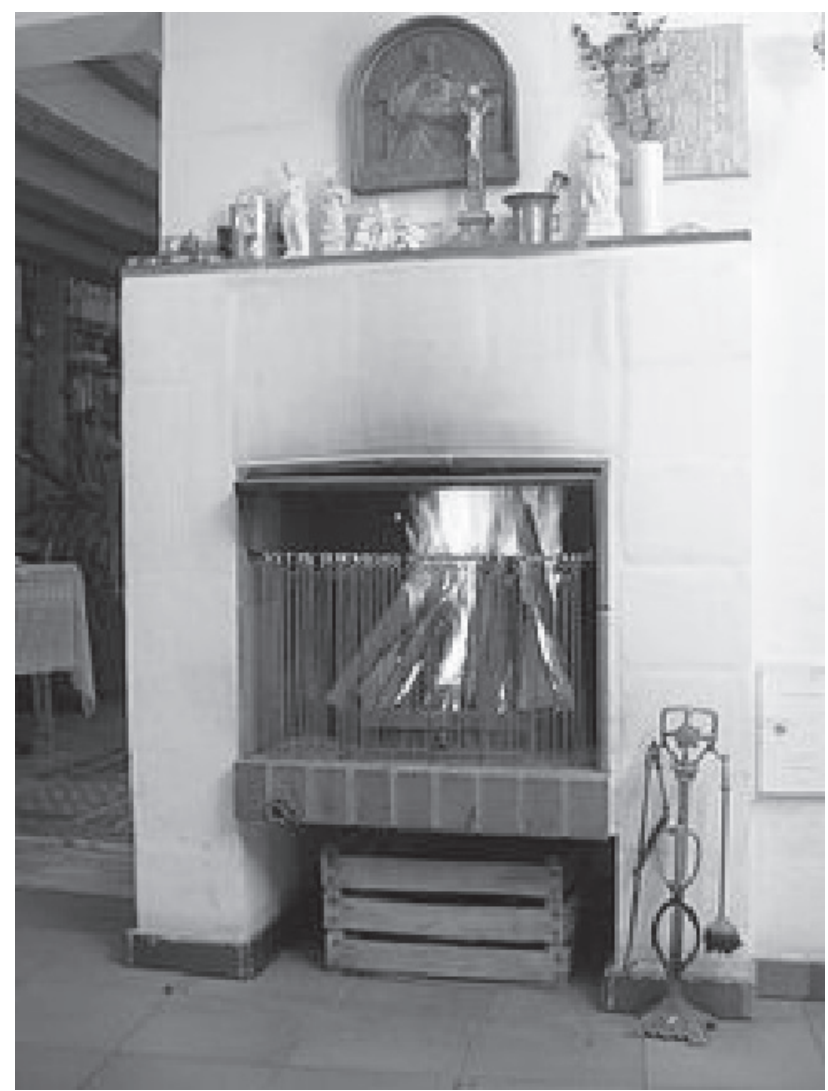

Gambar 05. Prapen Modern

menjadi salah satu bentuk kearifan local yang telah bertransformasi secara lintas budaya dan pada akhirnya melahirkan nilai budaya nasional. Perapen merupakan warisan masa lalu leluhur warga pande yang selanjutnya menjadi refleksi masyarakat penuturnya. Dalam dialektika hidup-mati (sesuatu yang hidup akan mati) tanpa pelestarian dan revitalisasi suatu saat akan mencapai kepunahan. Mengingat di zaman modern sikap masyarakat yang semakin pragmatis dan lebih berpihak pada tekanan dan kebutuhan ekonomi.

Tradisi memang unik, namun tradisi dapat bertahan karena terus dilanjutkan oleh generasi berikutnya. Dari tradisi pula mereka terus berkarya, mengikuti jejak nenek moyang meski era sudah berbeda. Mempertahankan identitas pande sebagai wujud bhakti kepada leluhur. Identitas juga sering memberikan tidak saja makna tentang pribadi seseorang melainkan juga ciri khas sebuah kebudayaan yang melatar belakanginya. Dari ciri itulah dapat diungkap keberadaan orang tersebut. Seperti usaha pande besi yang hingga kini masih eksis, suara besi ditempa memekakkan telinga. Ketika sinar matahari perlahan mulai tertutup mendung, sesekali suara itu hilang, berganti dengan bau 
arangyang terbakar hingga asapnya membubung ke udara.

Menjadi seorang pande besi tidaklah mudah, selain bakat dan keturunan seorang pande besi memiliki kewajiban untuk prihatin dengan laku berpuasa dan selalu berdoa sebelum membuat senjata agar bertuah. Irama pukulan besi, pengaturan pembakaran besi yang dipanaskan sebelum dipukul harus dipelajari dari para sesepuh (Mpu). Keahlian khusus sangat diperlukan karena saat mendesain alat pertanian selain teori, fisik juga harus kuat dan memiliki kreativitas yang tinggi (Jro Mangku Pande, 2017).

\subsection{Asal-usul Warga Pande di Bali}

Pande yang dimaksud dalam tulisan ini adalah keturunan (clan), soroh dari seseorang yang leluhurnya dahulu mempunyai profesi 'memande' baik membuat alat dari logam berupa perunggu (gong, alat-alat keagamaan dan lain-lain), berupa besi (cangkul, pisau, tombak, keris dan lain-lain), berupa emas dan perak (perhiasan, alat-alat keagamaan dan lainlain) semua digolongkan dengan istilah anggtandring dan angaluh). Memande adalah suatu pekerjaan yang hasilnya sangat diperlukan oleh seluruh lapisan masyarakat. Memande dan berdagang adalah profesi para pande sejak dahulu.

Pada awalnya warga pande tinggal di suatu tempat dengan berkelompok. Namun begitu menemukan tempat baru dimana mereka dibutuhkan mereka dengan cepat berpencar menjalankan profesinya di tempat baru, dan pada akhirnya mereka dipersatukan kembali ikatan kekerabatannya dalam adat keagamaan terutama pada hari Tumpek Landep. Selain berkelompok, keberadaan warga pande bisa di lihat dari symbol-simbol seperti yang sudah disebutkan di atas. Masyarakatnya memiliki teknik dan kemampuan khusus serta professional sehingga bergelar Mpu.

Zaman dahulu hanya warga pande yang bisa membuat alat/barang dari logam sehingga keberadaannya diperkirakan sezaman dengan mulainya zaman logam. Dr. R.Soekmono, dalam bukunya "Sejarah Kebudayaan Indonesia I" menyatakan kebudayaan logam berasal dari luar Asia Tenggara. Demikian juga apabila warga pande menggunakan system keturunan 'purusa' diperkirakan berasal dari luar Asia Tenggara.
Mereka berasal dari satu keluarga yang menemukan teknik pengolahan logam menjadi alat keperluan manusia. Kebudayaan logam di Indonesia termasuk satu golongan dengan kubudayaan logam Asia yang berpusat di Dongson. Sebelum menyebar di Nusantara, sebagian besar dari mereka bermukim di Dongson (Teluk Tonkin) mengerjakan alat-alat dari perunggu maupun besi.

Sekitar 300 tahun masehi mereka bermukim di Dongson dan diperkirakan sebagai cikal bakal pande yang ada di Nusantara kemudian. Perpindahan mereka ke Nusantara pada zaman perunggu \pm 2500 tahun SM bersama dengan kelompok penduduk lain yang lebih besar. Awal abad VI Masehi memasuki zaman Bali Kuno datang ke Bali Rsi Markandeya menyebarkan ajaran Hindu dan membawa sejumlah pekerja. Beliau juga membawa warga pande dari Jawa. Warga pande yang dibawa oleh Rsi Markandeya bermukim di sekitar desa Taro, sekitar danau batur, danau Tamblingan dan Besakih.

Masih di abad VI datang juga ke Bali salah seorang yang beragama Hindu bernama Sri Agni Jaya Sakti menjadi salah satu pengikut Sang Aji Saka namun beliau seorang Brahmana dan kedatangannya bersama-sama pendeta SiwaBudha. Ajaran Hindu yang beraliran Brahmana dibawa Sri Agni Jaya Sakti untuk diterapkan kepada masyarakat sekitar. Adapun ajaran beliau antara lain:
a) Tentang cara membuat senjata seperti tombak, keris dan mantramnya
b) Tentang memilih baik buruknya senjata yang dinamakan 'carcaning keris'.
c) Tentang pakaian perang, tulisan-tulisan yang dianggap bertuah dan mantramnya.
d) Tentang siasat perang.

Dari ke empat ajaran yang dibawa Sri Agni Jaya Sakti, ajaran pertama dan ke dua sangat berkaitan dengan keahlian/profesi para pande. Hanya pande, yang memiliki mantram dalam pembuatan senjata dan mengerti serta menghayati carcaning keris. Ajaran ketiga dan keempat sangat terkait dengan ajaran pertama dan kedua dengan harapan ada peningkatan persepsi seorang prajurit tentang cara memainkan senjata dalam perang, mengatur siasat perang. Benar cerita orang-orang terdahulu bahwa seorang pande selalu berada di depan sebagai pemuka dalam peperangan 
karena tahu dan mengerti cara penggunaan senjata yang dibuatnya termasuk mantranya (pasupati).

Berikutnya, datang pula para pande bersama Sri Kesari Warmadewa secara berkelompok di empat tempat yaitu; kelompok pande yang berdiam di daerah Besakih dan sekitarnya; kelompok pande yang berdiam di sekitar daerah Renon; kelompok pande yang mendiami pinggiran danau Tamblingan; dan kelompok pande yang tinggal di Pejeng. Dari keempat tempat pemukiman tersebut pande danau Tamblingan mendapat perlakuan istimewa karena jenis barang yang dihasilkan lebih istimewa dan skill/kepandaiannya lebih unggul. Mereka dibebaskan dari segala pajak yang semestinya wajib dibayar.

Terpisah dan terpecahnya warga pande yang bermukim di danau Tamblingan, karena pada saat itu Raja Sri Tapolung yang bergelar Bhatara Ćri Asta Asura Ratna Bumi Banten menyatakan diri tidak lagi tunduk kepada kekuasaan Raja Jawa (Majapahit). Akhirnya raja Majapahit Sri Hayam Wuruk mengirim pasukan untuk menyerang Bali sebagai hukuman atas sikap Raja Sri Tapolung. Sasaran utamanya adalah warga pande yuang berdiam di danau Tamblingan karena diperkirakan senjata para penguasa Bali disimpan di daerah ini. Penduduk pinggiran danau Tamblingan banyak yang melarikan diri dan bersembunyi di hutan sebelah Barat danau (daerah Gobleg).

Penguasa Bali setelah Sri Tapolung adalah Dalem Ketut Ngulesir (Semara Kepakisan) dengan istananya berpusat di Gelgel merasa perlu memanggil kembali ke asalnya para pande yang lari meninggalkan danau Tamblingan. Keempat kelompok pande pengikut Sri Kesari Warmadewa dinamakan pande Bang/Bang Kemaon atau pande Tamblingan. Pada zaman ini pande yang datang ke Bali merupakan prajuritprajurit Majapahit yang bukan orang sembarangan seperti Mpu Brahma WIsesa dan Mpu Lelumang. Adanya ikatan kembali dengan Majapahit atas dinobatkannya Dalem Semara Kepakisan sebagai raja Gelgel, diminta simpati rakyat Bali agar tidak mengadakan pemberontakan di kemudian hari.

Sebelumnya memang telah terjadi pemberontakan Takawa tahun 1345 dan Makambika tahun 1347, keduanya keluarga raja Pejeng. Penataan kembali daerah yang terkena dampak perang, maka oleh raja Dalem Semara Kepakisan dibuatkan keputusan sebagai berikut.

a) Pura Besakih dijadikan pura kerajaan pusat seluruh Bali;

b) Pura Dasar di Gelgel ditingkatkan statusnya menjadi Pura kerajaan sama statusnya dengan Pura Pusering Jagat pada zaman kerajaan Bedahulu;

c) Kaum Pasek Bendesa turunan Bali asli memegang kekuasaan di tiap-tiap daerah dan kahyangan menjadi pembesar atau tabeng puri;

d) Kaum Pande turunan Bali asli yang mahir dalam pembuatan senjata juga dijadikan pembesar mengepalai peralatan dari besi.

Para pande akan dipindah tempat ke desa baru yang belum ada pandenya terkadang atas kehendak sendiri atau perintah penguasa. Demikian seterusnya sehingga sukar membedakan pertalian antara pande-pande yang berbeda masa kedatangannya. Berikutnya pada saat Dalem Bekung berkuasa, kerajaan Gelgel terpecah terutama yang merasa keturunan Majapahit. Akibat keikutsertaan para pande memberontak raja, akhirnya Pura Dalem Tusan (Pura Pande yang dibuatkan oleh Dalem Gelgel kepada sentana Sire Tusan lama tidak terurus, tidak diberi sesajian karena situasi kerajaan yang sangat genting. Ketika Ida Dalem dikuasai oleh Ida Sanghyang Sengara (penasehatnya) saat itu pula para pande seluruhnya ikut terbunuh. Namun ada satu orang pande yang disembunyikan di bawah penguasaan Ida Sanghyang Ibu yang disembunyikan oleh Jangga Wadita di bawah air terjun Bantang Matiyem (disarikan dari beberapa sumber). Demikian sekilas asal-usul warga pande di Bali, sedangkan warga pande di zaman modern hanyalah keturunan yang mewarisi tradisi leluhur walaupun pekerjaannya tidak lagi sebagai seorang pande (memande).

\section{PENUTUP}

Warga pande yang dikenal di Bali hanyalah sebagai keturunan atau soroh (clan) yang memiliki keahlian dalam mengolah logam (memande). Profesi memande tetap eksis hingga saat ini disebabkan oleh berbagai perkembangan dan pengaruh kerajaan di masa 
lalu. Sebaran warga pande ada di berbagai wilayah kabupaten/Kota di Bali. Adanya ciri tertentu yakni ciri fisik, salah satunya adalah keberadaan per-api-an (perapen) tempat para pande melakukan aktivitas, ritual Tumpek Landep dan ciri simbolik berupa nama, warna, serta tradisi.

Profesi sebagai pande besi disamping merupakan pekerjaan pokok, juga merupakan keyakinan yang telah diwarisi secara turuntemurun menjadi bentuk penghormatan kepada leluhur. Dengan demikian warga pande tidak dapat dipisahkan dari perapen walaupun dalam kesehariannya tidak semua pande melakukan aktivitas memande. Perapen menjadi salah satu symbol penguatan identitas bagi warga pande.
Warga pande yang ada di Bali keberadaannya melalui tahapan perjalanan sejarah yang amat panjang dan berliku. Menurut catatan sejarah, kedatangan para pande di Bali seiring dengan datangnya para penguasa Majapahit. Namun demikian dari masa pra Hindu (Bali Kuno) masyarakat sudah mengenal cara pembuatan peti batu (sarkopagus) menandakan bahwa saat itu sudah ada masyarakat yang memiliki skill/ ketrampilan seperti seorang pande. Ketika memasuki zaman Bali Tengahan semakin nyata karena para penguasa sangat membutuhkan hasil karyanya, hingga Bali Modern, pande tetap eksis melayani kebutuhan masyarakat akan peralatan dalam kehidupan sehari-hari.

\section{DAFTAR PUSTAKA}

Guermonprez, Jean Francois.1987. Soroh Pande di Bali: Pembentukan Kasta dan Nilai Gelar. Denpasar: Udayana University.

Muhtadi, Dedi. 2011. Ketika Kearifan Lokal Tergerus Zaman. Jakarta: Kompas 23 April 2011.

Purna Jiwa, Pande Made. 2013. Prasasti dan Babad Pande: Mencari Jati Diri, Mengamalkan Bisama Batar Kawitan Menuju Ajeg Bali. Surabaya: Paramita

Ritiaksa, I Wayan. 2013. Bolong dan Gilik. Denpasar: Paramita.

Sumual. H. N. 1995. Baku Beking Pande. Manado: Bina Insani.

Titib. I Made. 2003. Teologi Dan Simbol-Simbol Dalam Agama Hindu. Surabaya: Paramita.

Titib. I Made. 2004. Purana: Sumber Ajaran Hindu Komprehensip. Surabaya: Paramita.

Wiana, I Ketut. 2000. Makna Agama Dalam Kehidupan. Denpasar: PT. Bali Post. 